\title{
Quantification of (p)rebound effects in retrofit policies - why does it matter?
}

\author{
Ray Galvin* and Minna Sunikka-Blank** \\ Department of Architecture, University of Cambridge, 1 Scroope Terrace, Cambridge CB2 1PX, UK. \\ *corresponding author. Email: rg445@cam.ac.uk Tel: +44 7758832415 \\ ** email: mms45@cam.ac.uk
}

\begin{abstract}
The 'prebound effect' characterises how average heating energy consumption in older homes is consistently lower than these buildings' calculated energy ratings, and helps explain why energy savings from thermal upgrades are often lower than anticipated. This paper explores the conceptual links between prebound and rebound effects and aims to quantify these behavioural effects. It applies the resulting mathematical model to empirical examples of actual and calculated energy consumption at scales of individual dwelling and national housing stock. These show that the rebound effect, as defined in econometrics literature, can only indicate proportionate reductions in energy consumption and can mask high levels of absolute consumption. The prebound effect, however, can identify under- and over-consumption regardless of rebound effects. A combination of high prebound effect and low income suggests fuel poverty, and the rebound effect here is less relevant regarding total energy consumption. Policymakers should identify housing with high prebound effects in order to eliminate fuel poverty, and be aware of inaccuracies in calculating payback time where economic viability of retrofits is mandated. Further research is needed to understand motivations and practices in households that have high prebound effects and to identify specific priority groups for thermal retrofit policy.
\end{abstract}

\section{Keywords:}

Prebound effect; rebound effect; thermal retrofits; energy policy; fuel poverty

\section{Introduction}

Nearly a quarter of low-income households in the EU cannot afford to have a comfortable indoor environment in their homes due to energy prices [1]. Retrofit programmes, driven by policy instruments such as the EU Energy Efficiency Directive 2012/7 [2]), can generate economic and societal benefits. However, the level of direct energy subsidies allocated to fuel poor households in some EU countries is much higher than budgets allocated to energy retrofit programmes, which could offer more sustainable support to fuel poor households and thereby address the cause of the problem. This calls for improvement of statistical data collection by providing more precise evidence of fuel poverty in the EU, and more linkage between the data in order to better identify the relationship between housing conditions and fuel poverty [3].

This paper aims to contribute to this discussion on housing conditions and fuel poverty in a policy context, by showing how the notion of the 'prebound effect', a term coined by Sunikka-Blank and Galvin [4], can be used as an indicator of fuel poor households, and setting this alongside established formulations of the 'rebound effect' (see list of special terms, symbols and abbreviations used in this paper, in Table 1).

It is first necessary to clarify the definitions and mathematics behind the prebound effect and the established rebound effect, which, we argue, is a key concept in setting accurate and equitable energy saving policy targets. The concept of the 'rebound effect' has a long history and is now deeply embedded in policy and academic discussion. This was initiated by Khazzoom's[5] empirical finding that energy savings were smaller than expected when new regulations demanded increases in the energy efficiency of electrical appliances. These regulations were enacted to reduce energy 
consumption in the wake of the oil crises of the early and mid-1970s, but Khazzoom found they were failing to do so proportionately, and might instead be having the opposite effect. He called this 'backfire', and in a later publication Khazzoom [6] linked this to a similar phenomenon observed by the $19^{\text {th }}$ century economist William Stanley Jevons [7].

In the numerous empirical studies that followed, it was generally found that 'backfire' seldom occurred, but still the energy savings were seldom proportionate to the energy efficiency increase. It seemed the energy efficiency increase was being divided into two parts: one portion went to reduce energy consumption, and the remaining portion was 'taken back' to increase the consumption of 'energy services' [8]. Energy services are the benefits people get from consuming energy, such as warmer homes, greater distances travelled, more goods produced, and brighter lighting. This twopart phenomenon came to have the label 'rebound effect', a term which first appears in academic literature in 1983 [9].

Due to the strong involvement of economists in rebound effect discussion, the concept of the rebound effect has been rigorously mathematically defined in econometric terms, and the mathematics of how it links the parameters of energy consumption, energy efficiency, energy services consumption and the price of energy have been developed in detail (see, e.g., [11,19]). In such literature the rebound effect is defined as the 'energy efficiency elasticity of energy services' (see definition in Section 2.2). There are other, alternative definitions of the rebound effect (see discussion in $[12,13])$, but the 'elasticity' definition found in economics literature tends to hold sway in most policy and planning discussion.

It is generally argued that there are four different forms of rebound effect: direct, indirect, economywide, and transformational [14]. The direct rebound effect is where consumers increase their energy service consumption in the same area that has the energy efficiency increase. With the indirect rebound effect, consumers use money saved as a consequence of an energy efficiency increase in one area, such as home heating, to increase their energy services in another area, such as holiday travel. The economy-wide rebound effect is a measure of the total rebound throughout a country's whole economy, as a consequence of all the energy efficiency increases in that country. The transformational rebound effect occurs when an energy efficiency increase results in social and organisational change, which increases the need or desire for the more energy efficient product. Direct rebound effects only are considered in this paper.

The difficulties of quantifying rebound effects are widely recognised, but estimates of the rebound effect and 'comfort taking' related to space heating generally lie within the range of 10-35\% [13]. Sorrell [15] suggests direct rebound effects are likely to decline in the future, if the demand for energy services saturates, and calls for $70 \%$ reductions in energy use in housing based on the engineering estimates.

Bodies such as the European Council for an Energy Efficient Economy emphasise the societal benefits of energy efficiency [16]. However, failure to take into account the rebound effect has been recognised as leading to shortfalls in achieving energy policy goals and as the reason actual energy savings fall short of estimates [15](. A useful feature of rebound effect mathematics is that this can be used in reverse, to estimate the actual level of energy efficiency that would be required, to achieve the reductions in energy consumption that policymakers are aiming for [16](see calculation methodology in [17]). Taking this several steps further, Cellura et al. [18] use an input-output model in a specific country's building and policy framework, to evaluate the energy and environmental effects of energy efficiency measures. These approaches to modelling makes the rebound effect a very useful concept for aiding policy on energy and environmental planning.

The rebound effect has been seen as a phenomenon that needs to be prevented, reduced and counteracted [19]. On the other hand, parties such as the International Energy Agency (IEA) have started to recognise the rebound effect as a co-benefit of energy efficiency policy that has wider social benefits, such as reduction of fuel poverty [20]. This is because the rebound effect implies an increase in the level of energy services, which is what is needed in fuel poor homes. 
The term 'prebound effect' gave a name to a phenomenon that was appearing persistently in a number of European housing stocks[4]. While the rebound effect focused on over-consumption after an energy efficiency upgrade, consistent evidence of under-consumption prior to or in the absence of energy efficiency upgrades was observed in Germany [21,22], France [23]; the Netherlands [24], Belgium [25] and the UK [26]. Four key observations made in relation to the prebound effect are: (a) for any specific value of calculated consumption there is a diverse range of actual consumption values; (b) on average in German datasets, actual consumption is about $35 \%$ below calculated consumption; (c) this gap increases as calculated consumption increases; and (d) for low energy houses (those with very low calculated consumption) the gap goes into reverse [4]. Consequently, the estimates of the economic viability of thermal retrofits are likely to be extremely over-optimistic, often by $50 \%$ or greater. Thermal retrofits 'cannot save energy that is not actually being consumed' [4, p. 265].

In recent academic literature the prebound effect is referred to in passing to give support for the idea that energy related occupant behaviour in homes is very different from that which is assumed in standard calculation methods for dwellings' energy consumption ratings (e.g. $[27,28,29])$, or that actual fuel savings after a retrofit are significantly less than predicted (e.g. [30]. It is also seen as evidence that energy saving in buildings depends on both the technical potential of the buildings, and the social potential of the occupants [31], and on the socio-technical nature of how these interact [32].

Table 1. Symbols, acronyms and nomenclatureused in this paper

\begin{tabular}{|c|c|}
\hline $\begin{array}{l}\text { Symbol, acronym } \\
\text { or term }\end{array}$ & Meaning \\
\hline$A$ & coefficient of $C$ in best-fit power curve for actual against calculated consumption \\
\hline$B_{E}$ & proportionate change in energy consumption \\
\hline$B_{\varepsilon}$ & proportionate change in energy efficiency \\
\hline$C$ & calculated (theoretical) energy consumption \\
\hline$D$ & exponenet of the best-fit power curve for actual against calculated consumption \\
\hline$E$ & actual energy consumption \\
\hline EC & European Commission \\
\hline EPC & Energy Performance Certificate \\
\hline kWh & kilowatt-hours \\
\hline $\mathrm{kWh} / \mathrm{m}^{2} \mathrm{a}$ & kilowatt-hours of energy consumed per square meter of floor area per year \\
\hline $\ln$ & the natural logarithm (of the quantity in the brackets) \\
\hline$P$ & prebound effect \\
\hline$R$ & Rebound effect \\
\hline$S$ & energy services \\
\hline U-value & coefficient of thermal retention, e.g. of walls and windows \\
\hline$\varepsilon$ & energy efficiency \\
\hline DENA & German energy agency (Deutsche Energie-Agentur) \\
\hline DIN & German Institute of Standards (Deutsches Instut für Normung) \\
\hline EU & European Uniom \\
\hline backfire & the situation where the rebound effect is greater than $1(=100 \%)$. \\
\hline elasticity & $\begin{array}{l}\text { (in economics) a measure of the proportionate change in one variable as a ratio of the } \\
\text { proportionate change in another variable }\end{array}$ \\
\hline prebound effect & $\begin{array}{l}\text { a measure of the shortfall in actual energy consumption as a proportion of theoretical, } \\
\text { calculated consumption }\end{array}$ \\
\hline rebound effect & $\begin{array}{l}\text { a measure of the proportion of an energy efficiency increase that is used to increase the } \\
\text { level of energy services, rather than decrease the level of energy consumption. }\end{array}$ \\
\hline
\end{tabular}


Although most policies and assessment tools are based on standardised assumptions regarding energy use rather than actual consumption, the prebound effect has been recognised by some policy makers, such as the Austrian Federal Ministry for Transport, Innovation and Technology [33] and the UK government [34], and has been set in the centre of concern as to how a system of calculated consumption could be devised which more accurately approximates actual consumption in Germany $[35,36]$. German and Austrian building industry publications have used the preboud effect as an argument as to why retrofitting to those countries' very exacting minimum standards do not always pay back through fuel savings (e.g. $[37,38])$. The notion of the prebound effect is frequently also used as an argument against wall insulation for older buildings (e.g. [39,40,41].

These authors' own publications have frequently referred to the prebound effect as an explanatory factor in fuel poverty and/or energy savings shortfalls in retrofits $[12,13,14,17,42,43,44,45,46,47,48]$, but what is lacking in academic literature is a definitive account of the mathematical relationship between rebound and prebound effects, with the implications for retrofit policy and fuel poverty that follow from this. This paper attempts to fill that gap.

Currently there is an assumption that if rebound effects are low, the energy and climate goals of thermal retrofits have been achieved, whereas if rebound effects are high, this indicates a problem $[49,50,51,52]$, and in such studies the prebound effect is not usually mentioned. This paper argues that the rebound effect, which essentially indicates a ratio between two proportions, and does not directly give an indication of absolute magnitudes of energy savings, cannot give a full picture of retrofit needs or success. It argues that the prebound effect, which gives a more direct indication of absolute levels of consumption, needs to be considered in setting more accurate and equitable policy targets and in assessing the success or otherwise of retrofits.

The remainder of this paper is structured as follows. Section 2 offers a mathematical development of the prebound effect and relates this to standard mathematics of the rebound effect. Section 3 analyses two case studies using the mathematical structure so developed. The aim of these two examples is not to make generalisations or claim to be universally representative, but they are used as practical cases to demonstrate the mathematics of these two behavioural concepts. The results of these analyses are discussed in Section 4, and Section 5 concludes.

\section{Mathematics}

\subsection{The mathematics of the prebound effect}

The notion of the 'prebound effect' was derived from the consistent finding that actual domestic heating energy consumption is, on average, lower than the theoretical, calculated level of consumption required to keep a dwelling comfortably warm in all rooms throughout the entire winter. This was found in all known, existing, published datasets of German housing sectors, and also in similar datasets from Belgium, France, the Netherlands and the UK. Readers are referred to discussion of these datasets in the original prebound effect paper [4], and to the data sources cited there, for details of their data collection, time-period, description of their representativeness, etc. The original mathematical description of the prebound effect was developed as follows.

Figure 1 is a plot from the combined German datasets used by Sunikka-Blank and Galvin [4] in their description of the prebound effect. These are datasets of calculated, theoretical heating energy consumption $C$ in German dwellings (horizontal-axis) and actual, measured consumption $E$ of the same dwellings (vertical-axis). The datasets were combined by weighting their values according to the number of data points in each dataset. The weighted average of the values is given by the solid line in Figure 1.

'Calculated consumption' is a theoretical figure used in building engineering in Germany and a number of other countries, to indicate how much heating energy would need to be consumed in a particular dwelling, for that dwelling to have a comfortable indoor temperature and air quality in all rooms, throughout the whole year. In Germany the parameters for this are defined in Standard DIN V 4108-6 of the German Institute of Standards (Deutsches Institut für Normung - DIN - www.din.de/). 
There is currently discussion among practitioners and academics as to how accurate calculated consumption ratings such as this are [53]. For the purposes of this paper, current values are accepted, but discussion is included in Section 4 on the difference that future changes in these calculation methodologies might make.

In Figure 1 the points where actual and calculated consumption would be equal are given by the straight diagonal line $E=C$. The prebound effect $P$ was defined by its initiating authors as the shortfall in actual as compared to calculated consumption, as a ratio of calculated consumption:

$$
P=\frac{C-E}{C}
$$

This can be expressed as a function of $C$ alone, if a formula is developed for the relationship between $E$ and $C$, over the range of the data points. This can be done by beginning with trial-and-error curvefitting. In Figure 1 the curve so fitted is the solid curved line. A simple formula which closely approximates this fitted curve is the power function:

$$
E=4.5 C^{0.641}
$$

This formula is represented by the curve given by the broken line in Figure 1. It should be noted that later research has found power curves of this form to give the most consistent lines of best fit for datasets such as these $[13,45,54]$.

Such curves have the general form:

$$
E=A \cdot C^{D}
$$

where $A$ and $D$ are constants.

Substituting (3) in (1) gives a general expression for the prebound effect in $C$ :

$$
P=1-A \cdot C^{D-1}
$$

In this case the formula is:

$$
P=1-4.5 C^{-0.359}
$$

This indicates how the prebound effect varies with calculated or theoretical consumption in the particular case of these combined datasets of German dwellings. Three features are clear from equations (4) and (3):

(a) Equation (4) indicates that the prebound effect $P$ is negatively correlated with the constant $A$, whereas equation (3) indicates that energy consumption $E$ is positively correlated with $A$. In other words, high prebound effects are associated with low levels of actual consumption, and vice versa.

(b) In equation (4) the prebound effect is negatively correlated with the exponent $D$, whereas, in equation (3), $E$ is positively correlated with $D$. Both $A$ and $D$ are constants for any particular dataset. This implies that datasets in which consumption is generally high are likely to have low prebound effects, whereas datasets of homes where consumption is generally low (such as in cases of fuel poverty) are likely to have high prebound effects.

(c) The prebound effect is positively correlated with theoretical, calculated energy consumption $C$. This means that, regardless of the type of home indicated by the constants $A$ and $D$ in a dataset, the higher the calculated consumption within that dataset, the higher the prebound effect is likely to be. This is most likely because, the harder a home is to heat (all other things being equal), the more likely it is that the occupants under-heat it. It should be noted that dwellings with high calculated consumption are frequently associated with low-income households [55].

This gives a general, qualitative picture of the sort of information the prebound effect can give. Where actual consumption is high compared to calculated consumption, the prebound effect is low; 
and where calculated consumption is high (i.e. the thermal quality of the dwelling is poor) the prebound effect is high.

This is as far as the original work on the prebound effect was taken. The following sub-section extends this into a discussion of the rebound effect.

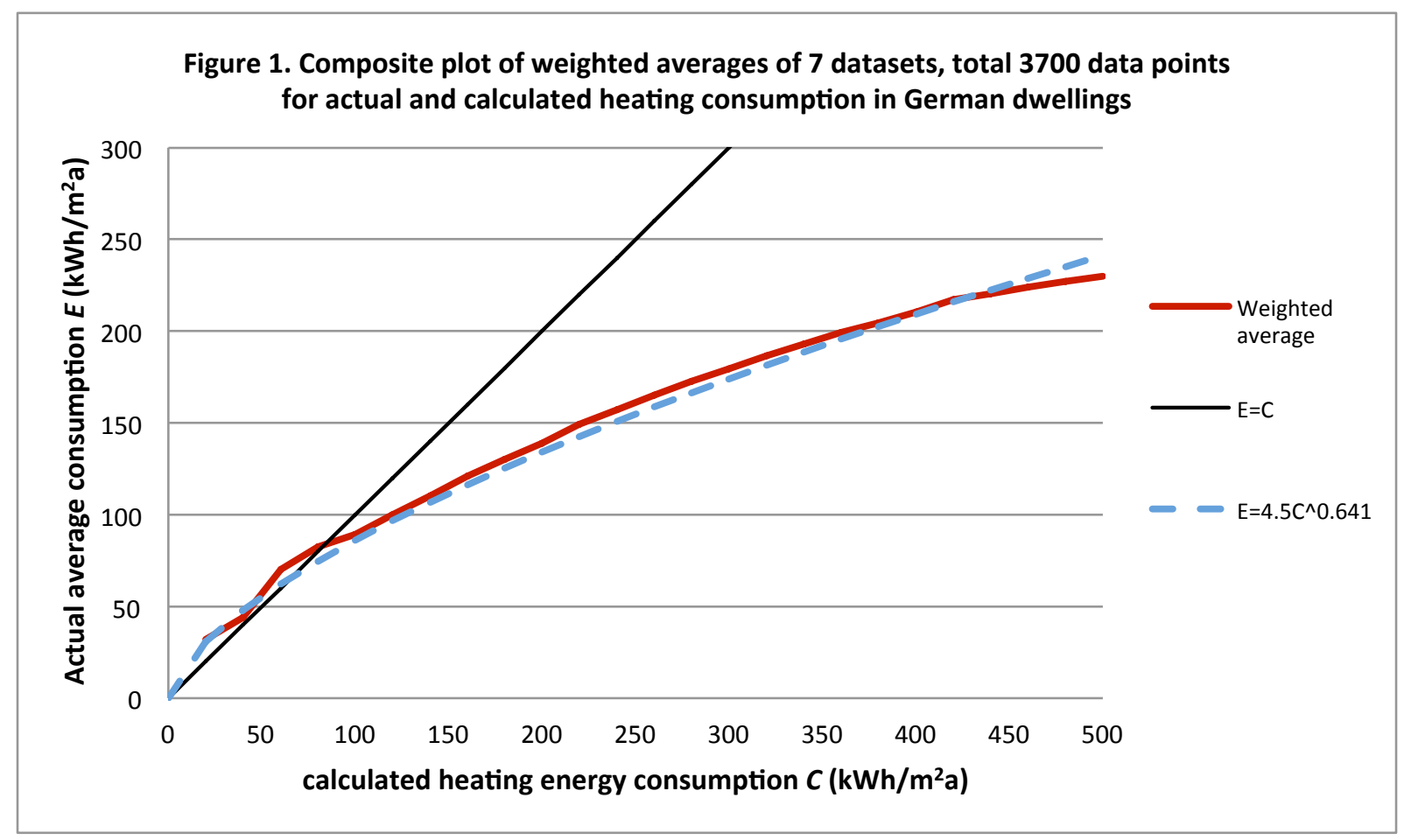

\subsection{The mathematics of the rebound effect}

The rebound effect is conceived in econometrics literature as an 'elasticity'. This is a relation which maps the ratio between a proportionate change in one parameter against a proportionate change in a second parameter. The 'elasticity' rebound effect is defined $[10,11]$ as the energy elasticity of energy services consumption, i.e. the ratio between a proportionate change in energy services consumption $S$ and the proportionate change in energy efficiency $\varepsilon$ :

$$
R=\frac{\partial S}{S} / \frac{\partial \varepsilon}{\varepsilon}
$$

The level of energy services is generally regarded as proportional to the energy consumption and the efficiency with which this energy is converted to these services [11]:

$$
S=\varepsilon \cdot E
$$

where $E$ = energy consumption. Substituting (7) in (6) and using the product rule gives an expression for the rebound effect in terms of energy efficiency and energy consumption:

$$
R=1+\frac{\partial E}{\partial \varepsilon} \cdot \frac{\varepsilon}{E}
$$

Where heating in buildings is concerned, energy efficiency $\varepsilon$ is generally taken to be inversely proportional to calculated consumption $C$ [12], i.e.:

$$
C=\varepsilon^{-1}
$$


Hence, if the relationship between calculated energy consumption $C$ and actual energy consumption $E$ is a power curve, as in Section 2.1 above, equation (3) can be rewritten:

$$
E=A \cdot \varepsilon^{-D}
$$

Substituting (10) in (8) gives an expression for the rebound effect for the case where equation (3) holds true:

$$
R=1+\frac{-D \cdot A \cdot \varepsilon^{-D-1} \cdot \varepsilon}{A \cdot \epsilon^{-D}}
$$

Simplifying (11):

$$
R=1-D
$$

This means that for any particular dataset of calculated and actual heating energy consumption, the rebound effect is a constant. Its magnitude depends entirely on $D$, the exponent of the power curve that bests fits the data points. This ratio stays constant no matter how high the calculated consumption is. In practical terms, this means that for any particular dataset such as that represented in Figure 1, if a large number of homes are thermally retrofitted, the average of their rebound effects will be $1-D$, regardless of how high their theoretical, calculated consumption was prior to their retrofits, or how low or high it is post-retrofit. This is because the 'elasticity' rebound effect is a behavioural response. It indicates the average magnitude of the proportionate shift in consumption that occurs when people can get more energy services for less effective cost.

It is also important to note that this analysis shows how the rebound and prebound effects have only one mathematical feature in common: they are both negatively correlated with the variable $D$. This variable represents the human factor in changes in consumption in relation to changes in energy efficiency. The higher the proportion by which users tend to increase their heating consumption when energy efficiency rises, the lower the variable $D$, therefore the larger the term $1-D$, therefore the larger the rebound effect, and the larger the reduction in the prebound effect. The other variables, $A$ and $C$, which occur only in the prebound effect formula, are quite different. $C$ is determined entirely by the thermal quality of the dwelling (a high $C$ correlates to low thermal quality, and vice versa). $A$ is determined by the average influence of human behaviour within the dataset, but not by changes in behaviour. A high value of $A$ indicates that the householders whose homes are represented in a particular dataset are high consumers, on average, regardless of the thermal quality of their homes. The rebound effect can give a figure for how much people's energy consumption reduces in proportion to how high it was previously, given a certain proportionate change in energy efficiency, but it gives no indication of what the magnitude of their energy consumption was or now is (hence $A$ cancels out in the rebound effect calculation, as seen in equations (11) and (12)). Nor does it relate this change to average consumption or theoretical, calculated consumption. The prebound effect, however, gives clear figures for the level of consumption in relation to the expected, calculated consumption, for situations both prior to and after a retrofit, for any chosen starting or finishing point. Hence it brings us closer to seeing what that actual changes in energy consumption are (not just the proportionate changes), as energy efficiency changes ${ }^{1}$.

\footnotetext{
${ }^{1}$ It should also be noted a rebound effect calculated by this method is the mid-point of a confidence interval. Calculating the confidence interval for an exponent of a power curve requires a log-log transformation of the data, whereupon the line of best fit becomes a straight line, and the confidence interval for the rebound effect is the confidence interval of the gradient of this line. A forthcoming paper by one of the authors develops this and applies it to a large range of datasets.
} 


\section{Case study examples}

\subsection{Calculated vs. actual consumption in French homes}

The implications of the theoretical points made in Section 2 become more focused when empirical examples are considered. We first look at the application of the mathematics of the ( $p$ )rebound effects in French houses, using a cross-sectional method ${ }^{3}$.

Figure 2 gives a scatterplot of calculated and actual heating energy consumption in a random selection of 700 French 'houses' (i.e. homes not in multi-apartment buildings), gathered by Cayla et al. [23], giving these dwellings' calculated and actual space heating energy consumption in 2006. Readers are referred to [23] for the details of data gathering, cleaning, etc. ${ }^{5}$. Based on equation (3), the best-fit power curve for this data is:

$$
E=9.52 C^{0.494}
$$

Therefore, based on equation (12), the rebound effect for these homes is:

$$
R=1-0.494=0.506 \approx 51 \%
$$

This means that if a large number of such dwellings were thermally retrofitted their average rebound would be $51 \%$, regardless of their calculated energy consumption prior to and after the retrofits.

The prebound effect, given by equation (4), is:

$$
P=1-9.52 \cdot C^{-0.51}
$$

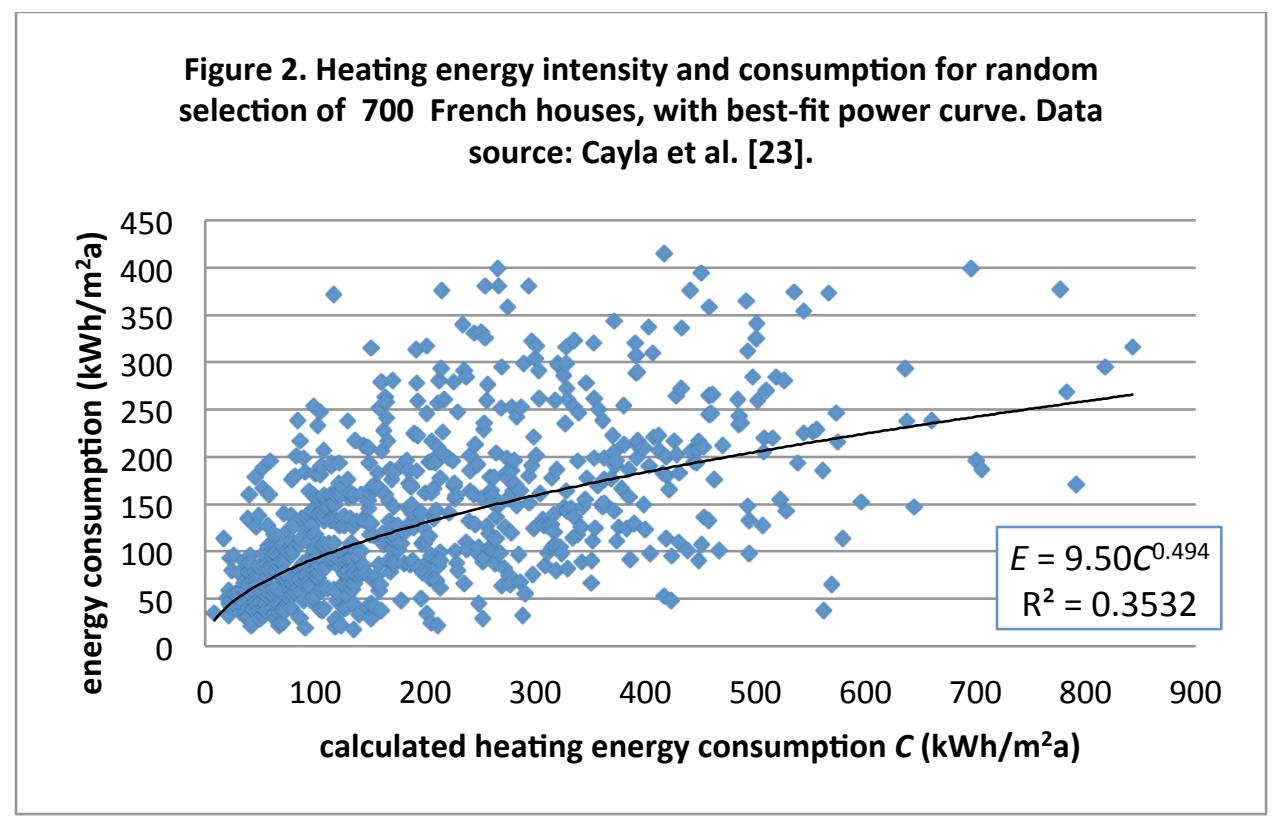

\footnotetext{
${ }^{3}$ The cross-sectional method used here takes a snapshot of a large representative sample, and uses the assumption that, on average, dwellings with calculated consumption $\mathrm{C} 1$ and actual consumption $\mathrm{A} 1$ would end up with actual consumption $A 2$ if their calculated consumption was reduced to $C 2$, where points $(C 1, A 1)$ and $(C 2, A 2)$ lie on the line of best fit. This is a standard econometric method of estimating elasticities, and is discussed in relation to space heating in $[13,45,54]$.

${ }^{5}$ Note that there is a wide scattering of points in this dataset. This is typical of such datasets, as there is wide individual variation in consumption patterns in dwellings, even where they have the same theoretical, calculated consumption levels. As mentioned in an earlier footnote, the $95 \%$ confidence interval for the exponent $D$ is the $95 \%$ confidence interval of the (linear) gradient of the log transformation of equation (3). In this case, the confidence interval is $44.92-54.74 \%$.
} 
In comparison to the German datasets in Figure 1, the constant $A$ is higher in the French dataset, which puts downward pressure on the prebound effect for all values of $C$. On the other hand, $D$ is lower in the French dataset, which puts upward pressure on the prebound effect for high values of $C$. The difference is seen in a specific example, as follows.

Consider a French house and a German home each with calculated consumption of $300 \mathrm{kWh} / \mathrm{m}^{2} \mathrm{a}$, which is about $30 \%$ above the average of German housing stock [56]. In each case, consider what happens with rebound and prebound effects if these homes are both retrofitted to give a calculated consumption of $100 \mathrm{kWh} / \mathrm{m}^{2}$ a, the current average ${ }^{6}$ mandatory standard in Germany for retrofits, and alternatively to $50 \mathrm{kWh} / \mathrm{m}^{2}$ a, the current German average new build standard. Assuming these homes perform as 'average' within their respective building stocks, the results are those given in Table 2, based on equations (4) and (12) ${ }^{7}$.

\begin{tabular}{|l|l|l|l|l|l|l|l|l|}
\hline \multicolumn{4}{|l|}{ German homes } & \multicolumn{3}{l|}{ French houses } \\
\hline$C$ & $A$ & $D$ & Rebound \% & Prebound \% & $A$ & $D$ & Rebound \% & Prebound \% \\
\hline 300 & 4,5 & 0,641 & 35,9 & 41,933 & 9,52 & 0,494 & 50,6 & 46,885 \\
\hline 100 & 4,5 & 0,641 & 35,9 & 13,858 & 9,52 & 0,494 & 50,6 & 7,394 \\
\hline 50 & 4,5 & 0,641 & 35,9 & $-10,480$ & 9,52 & 0,494 & 50,6 & $-31,510$ \\
\hline
\end{tabular}

Table 2. Rebound and prebound effects for datasets of German homes and French houses, for three distinct levels of calculated consumption. Source: own calculations from Sunikka-Blank and Galvin [4] and Cayla et al. [23].

As Table 2 indicates, the rebound effect for French houses is significantly higher than for German homes, at $51 \%$ compared to $36 \%$. Using the rebound effect alone to compare the energy saving gain from retrofitting the two housing stocks would therefore lead to the conclusion that retrofitting German homes brings greater energy saving gains on average, because their rebound effects are lower.

However, a more nuanced picture is given when the prebound effect is included in the discussion. For thermally poor homes, represented by a high level of theoretical, calculated consumption (here $300 \mathrm{kWh} / \mathrm{m}^{2} \mathrm{a}$ ), the prebound effect is higher for French houses (47\%) than for German homes $(42 \%)$. This means that, on average, French houses under-consume compared to German homes, in relation to their theoretical, calculated consumption at this (higher) end of the scale.

Further, from equations (5) and (15) it can be seen that the prebound effect in the French dataset remains higher than that in the German dataset for dwellings with calculated consumption greater than $145 \mathrm{kWh} / \mathrm{m}^{2}$ a. Below that figure the prebound effect is higher in the German dataset.

French households who are in homes of low thermal quality therefore, on average, tend to underconsume more deeply compared to German households living in homes of low thermal quality. German households tend to spend more to keep warm in these (mostly older) homes. Hence, retrofitting an average French house to a modest level - say around $120 \mathrm{kWh} / \mathrm{m}^{2} \mathrm{a}-$ will actually save more energy than retrofitting a German house to the same level. Further, a case could be made that

\footnotetext{
${ }^{6}$ The precise minimum standard for any particular buiding varies according to its geometry and size. These figures are averages over all domestic buildings.

${ }^{7}$ Intuitively it might seem that the rebound effect depends on the level of consumption. However, as is proven in [45] and [54], if a power curve is a fair approximation of the best fit curve of the data, the rebound effect is independent of the level of consumption. This can also be shown by performing a log-log transformation of the data. This produces a straight line as the best-fit line, i.e. it has a constant gradient, the value of which is 1 minus the rebound effect.
} 
the social gain is greater from retrofitting thermally poor French homes, as high prebound effects indicate that a house is not as warm as it needs to be for good health and comfort.

Why, then, is the average rebound effect higher in French houses than in German homes? The reason is that the prebound effect in French houses of very high thermal quality is lower than that in German homes of high thermal quality: French households tend to over-consume more liberally in low energy homes, i.e. when it is cheap to do so. As Table 2 shows, at a calculated consumption of $100 \mathrm{kWh} / \mathrm{m}^{2} \mathrm{a}$, French houses show a prebound effect significantly lower than German houses, at $7.4 \%$ compared to $13.9 \%$, and the discrepancy widens to $-31.5 \%$ compared to $-10.5 \%$ for a calculated consumption of $50 \mathrm{kWh} / \mathrm{m}^{2}$ a. Setting $P=0$ in equation (15) indicates that the prebound effect is zero for French houses where calculated consumption $C$ is $83 \mathrm{kWh} / \mathrm{m}^{2}$ a. This suggests that retrofitting French houses to a higher thermal standard than this (i.e. a lower value of $C$ ) is likely to bring less savings than anticipated. At this point the house is giving full thermal comfort, and retrofitting it to a higher standard simply results in energy being wasted, i.e. a negative prebound effect. The corresponding value of $C$ for German homes is $65.2 \mathrm{kWh} / \mathrm{m}^{2}$ a.

A further point is that average actual consumption in the French dataset is $144 \mathrm{kWh} / \mathrm{m}^{2} \mathrm{a}$, whereas for German homes it is around $150 \mathrm{kWh} / \mathrm{m}^{2} \mathrm{a}$ [56]. The difference between these is not great, but it should be noted that 'houses' only are included in the French dataset, whereas the German dataset includes both houses and apartments. A further dataset made available to these authors by Cayla et al. indicates that French apartments consume, on average, around $89 \mathrm{kWh} / \mathrm{m}^{2}$ a. Hence average consumption for French homes is most likely significantly lower than for German homes.

By including the prebound effect it becomes clear that:

(a) Because of the profile of the prebound effect, retrofitting French houses to a modest theoretical consumption level of around $120 \mathrm{kWh} / \mathrm{m}^{2}$ a, on average, can theoretically save more energy than retrofitting German homes to the same standard.

(b) Due to the reduction of fuel poverty and improved thermal comfort, there is more social gain to be achieved from retrofitting French houses to about this standard or somewhat better.

(c) Again because of the profile of the prebound effect, retrofitting French houses to very high thermal standards (under $83 \mathrm{kWh} / \mathrm{m}^{2}$ a) is likely to bring considerable over-consumption, whereas over-consumption in thermally efficient German homes, on average, is less evident until the standard reaches about $65 \mathrm{kWh} / \mathrm{m}^{2} \mathrm{a}$.

We do not know why the profile of the prebound effect differs so significantly between French and German homes. This could be because of socio-cultural factors related to heating practices or simply awareness of energy use.

\subsection{Thermally retrofitted home in the UK}

Considering the rebound and prebound effects is also of interest to a homeowner who wants to take up economically feasible energy efficiency measures. As an empirical example of using the mathematical structure of these behavioural effects a three-bedroom, semi-detached house of floor area $75 \mathrm{~m}^{2}$, in Cambridge, UK, was investigated by the authors prior to, during and after its retrofit with external wall insulation and a heat-recovery ventilator. The case study example was chosen as a representative house of one of a number of types in Cambridge, and the thermally retrofit process was directly observed by the researchers.

The house was built in the 1930s and has solid walls. It already had double-glazed windows, loft and ground floor insulation, and gas central heating with thermostatic radiator valves. However, its poor orientation to the sun, the poor thermal quality of the uninsulated walls, and the need to ventilate bathroom areas manually made it difficult to heat adequately. The house was occupied by two working adults who are usually at home in the evenings and weekends, and one of whom frequently works from home. Gas was only used for space heating, as both the cooker and shower were electric. Hence these consumption figures do not need a rule-of-thumb adjustment for the portion used in cooking and hot water. 
An independent energy audit by a Green Deal advisor estimated that the annual space heating energy requirement, achieved with gas central heating, was 15,000 kWh, giving a theoretical, calculated heating energy consumption $C$ of $200 \mathrm{kWh} / \mathrm{m}^{2}$ a. The actual space heating energy consumption, averaged over the three years prior to the audit, was $6,550 \mathrm{kWh}$, giving an actual consumption $E$ of $87 \mathrm{kWh} / \mathrm{m}^{2}$ a. Using equation (1) this gives a prebound effect of $56.5 \%$. The retrofit was designed to reduce the theoretical space heating energy consumption to around $100 \mathrm{kWh} / \mathrm{m}^{2} \mathrm{a}$. Note that pre-retrofit actual consumption was even lower than this.

A pre-retrofit prebound effect of $56.5 \%$ is very high compared to the average of both French and German datasets for this level of $C$. This can be indicative of 'fuel poverty' [57], where the thermal quality of a home is so poor that occupants cannot afford to heat it to a healthy, comfortable level [55]. It also means that the energy saving estimates given by the independent energy audit were highly overestimated and the estimate for payback time of the energy efficiency measures, if considered in fuel savings, was inaccurate. The Green Deal policy only finances measures that are considered 'economically feasible' and comply with the 'golden rule', i.e. pay back in fuel savings in 25 years. In this case there was a $£ 6,000$ grant towards the retrofit investment while the remaining retrofit costs of $£ 3,500$ were expected to pay back through savings in energy bills within the 25 -year time frame. However, based on the actual pre-retrofit consumption figures (i.e. including the prebound effect), and a gas price of $£ 0.05 / \mathrm{kWh}$, the $£ 3,500$ would never payback if the household heated to the theoretical, post-retrofit level of around $100 \mathrm{kWh} / \mathrm{m}^{2}$ a, since this would represent an increase in energy consumption ${ }^{8}$. To payback within 25 years the household would have to reduce its actual consumption by $37 \mathrm{kWh} / \mathrm{m}^{2}$, i.e.to $50 \mathrm{kWh} / \mathrm{m}^{2}$ a, which is half the calculated requirement for full thermal comfort.

The rebound effect for an individual dwelling retrofit can be calculated from the general solution to equation (8), namely:

$$
R=1+\frac{\ln \left(B_{E}\right)}{\ln \left(B_{\varepsilon}\right)}
$$

where $B_{E}$ is the proportionate change in actual energy consumption and $B_{\varepsilon}$ the proportionate change in energy efficiency (= the reciprocal of the proportionate change in calculated energy consumption). Using this formula, if the household heated to the calculated level of $100 \mathrm{kWh} / \mathrm{m}^{2}$ a after the retrofit, its rebound effect would be $120 \%$. This is termed 'backfire' in economics literature, as it represents higher consumption after the energy efficiency upgrade than before it. This is significantly higher than an estimated UK average of around 35\% [17]. The negative policy connotations of 'backfire' do not sit well with the idea of a household merely consuming the amount of energy required for full thermal comfort. Table 3 summarises these findings.

\begin{tabular}{|c|c|c|c|c|c|c|}
\hline \multicolumn{2}{|c|}{$\begin{array}{l}\text { Calculated } \\
\text { consumption } C \\
\left(\mathrm{kWh} / \mathrm{m}^{2} \mathrm{a}\right)\end{array}$} & \multicolumn{2}{|c|}{$\begin{array}{l}\text { Actual consumption } E \\
\left(\mathrm{kWh} / \mathrm{m}^{2} \mathrm{a}\right)\end{array}$} & \multirow{2}{*}{$\begin{array}{l}\text { Rebound } \\
\text { effect (\%) } \\
\text { if house- } \\
\text { hold heats } \\
\text { to } \\
\text { expected } \\
\text { level }\end{array}$} & \multirow{2}{*}{\begin{tabular}{|l|}
$\begin{array}{l}\text { Prebound } \\
\text { effect (\%) }\end{array}$ \\
$\begin{array}{l}\text { Pre- } \\
\text { retrofit }\end{array}$ \\
\end{tabular}} & \multirow{2}{*}{$\begin{array}{l}\begin{array}{l}\text { Prebound } \\
\text { effect (\%) }\end{array} \\
\text { Post-retrofit } \\
\text { (for } 100 \\
\mathrm{kWh} / \mathrm{m}^{2} \mathrm{a} \text { ) }\end{array}$} \\
\hline $\begin{array}{l}\text { Pre- } \\
\text { retrofit }\end{array}$ & $\begin{array}{l}\text { Post- } \\
\text { retrofit }\end{array}$ & $\begin{array}{l}\text { Pre- } \\
\text { retrofit }\end{array}$ & $\begin{array}{l}\text { Post- } \\
\text { retrofit } \\
\text { (expected) }\end{array}$ & & & \\
\hline 200 & 100 & 87 & 100 & 120 & 56.5 & 0 \\
\hline
\end{tabular}

\footnotetext{
${ }^{8}$ It is rare for actual consumption to increase after a retrofit, but it can happen. A typical situation is where householders realise, after a retrofit, that they would no longer be throwing money out the window by having their radiators turned on in all rooms, all the time. However, there is no claim here that the household increased their consumption to this level. The example is merely to see what the rebound effect and payback time would be if they did,
} 
Table 3. Space heating energy consumption, rebound and prebound effect parameters for a thermal retrofit of a Cambridge, UK, home.

A much discussed question among energy policy and planning is, what levels of rebound effect can be expected from fuel-poor homes? Concern is sometimes expressed that rebound effects are very high when fuel-poor homes are retrofitted [52], and that this could make governments reluctant to incentivise such retrofits. However, when the prebound effect is brought into the discussion it is seen that this concern is somewhat misplaced. The high prebound effect prior to retrofitting indicates that this house was under-consuming by a significant margin. A retrofit that is successful from a social point of view would reduce the prebound effect, narrowing the 'discomfort' gap between calculated and actual consumption. This would amount to a high rebound effect, but it would not imply that this house would become an over-consumer. Even where the rebound effect is higher than $100 \%$ ('backfire'), this does not necessarily imply that the retrofit 'backfired' in terms of its purposes. The rebound effect, where the occupants can keep the indoor temperature of their home at a comfortable level, would simply bring its consumption level to a more normal standard for a retrofitted home.

As noted above, the retrofit was designed to give a calculated consumption level of about $100 \mathrm{kWh} / \mathrm{m}^{2}$ a. If the actual consumption level after the retrofit increases to that level, thereby reducing the prebound effect to zero, the actual increase in consumption would be $13 \mathrm{kWh} / \mathrm{m}^{2}$ a, or $975 \mathrm{kWh}$ per year for the house, bringing its heating consumption to $7,500 \mathrm{kWh}$ per year. This is significantly lower than the average for the UK, which is well over 12,000kWh [64]. Using the rebound figure out of context would therefore be misleading regarding the total energy consumption of this house.

\section{Discussion}

The findings have the following policy implications, which we set in the UK context in the first instance, but also see them to be applicable in the EU.

Firstly, if policymakers had data on the prebound effect, based on calculated and actual energy consumption, they would be able to identify households that are under consuming. Not all households who live in homes with high prebound effect are fuel poor. Keeping a low indoor temperature or heating only certain rooms in under-occupied homes can be a personal choice. Therefore a high prebound effect might not always indicate discomfort in the home, just as a low prebound effect might be necessary for some, such as elderly people, who may need higher indoor temperatures constantly. 'Full thermal comfort' is a subjective measure. In Germany, for example, it is defined by the German Institute for Standards (see above). The internationally used ASHRAE standard has a similar basis. Although these are based on laboratory studies of human comfort levels, it is widely admitted that individual's needs and perceptions of thermal comfort can vary over a wide range [58] and thermal comfort is a highly socio-cultural construct, as well as having biological parameters and limits [59]. However, if the preboud effect is combined with information about household income, it is possible to identify households who are fuel poor and need support for thermal retrofits.

Fabbri [60] has suggests an index to evaluate fuel poverty based on (low) income, energy prices and (poor) building energy performance. Income and energy prices can be obtained from various existing databases but, as recognised by Fabbri [60], poor energy performance is a more complex factor due to variety of the building stock and the number of variables. A poor energy performance does not necessarily indicate low thermal comfort, as middle- or high-income households can afford to compensate for poor technical performance with their heating patterns. This paper suggests that we need to look at the income level and the gap between the calculated consumption and the actual, 
measured consumption, i.e. the prebound effect. As the prebound effect itself includes a behavioural response to energy prices, these two factors are sufficient to identify the fuel poor.

Despite the fact that the UK is one of the EU countries where fuel poverty is recognised in energy policies, the UK Government has been reducing support for thermal retrofits, such as the Green Deal, which was scrapped in 2015. The Energy Companies Obligation (ECO) scheme, introduced in 2013, imposes energy saving obligations on energy companies. The Carbon Saving Community Obligation (CSCO) and the Home Heating Cost Reduction Obligation (HHCRO) are specifically targeted at lowincome households. Further, the British government announced in 2015 that private landlords would not be able to unreasonably refuse requests from their tenants for energy efficiency improvements, where financial support, such as ECO, is available. However, the housing shortage in the UK and the difficulty of finding private rental properties in many areas make these demands by tenants, in most cases, highly unlikely. Yet societal benefits from the programs tackling fuel poverty are obvious. For example, as a result of the Warm Front Scheme, which gave grants of up to $£ 3,500$ for energy efficiency measures, a decrease in anxiety or depression by $50 \%$ was reported (from 300 to 150 per 1000 occupants), while the beneficiaries of the scheme were $40 \%$ less likely to report a high level of psychological distress, and there were positive impacts on the children's respiratory problems [3]. Considering these kinds of societal benefits, fuel poor households should be a policy priority, regardless of the potentially high rebound effect that will only ensure that their homes are heated to an adequate level.

However, as found by Boardman [61], many of the most severely fuel poor households can be reluctant to get involved in thermal retrofit programmes (she calls them 'the hidden fuel poor'), and alternative policy approaches are needed. She suggests a combination of a community energy scheme that is usually need-driven and initiated by a third-sector or voluntary group, and an areabased approach, led by the local authority and possibly legislation driven. If local authorities were to adopt an area based approach where several properties were improved in the same street, the use of the prebound effect as an indicator of priority areas combined with income level data could be a serviceable approach that would offer metrics for priority area selection and set a quantitative criteria as to which households qualify for a grant.

Secondly, the two empirical examples show how important it is for policy instruments that include a criterion of 'economic viability' to consider behavioural effects, whether in a regulatory instrument as in Germany [47] or a fiscal instrument [62]. A homeowner's decision as to whether to invest in energy efficiency measures greatly depends on the payback time. Therefore the financial feasibility of thermal retrofit measures greatly depends on accurate actual energy consumption figures.

The advice given in EU-driven Energy Performance Certificates (EPCS) is based on estimated consumption, whereas in California, for example, the energy audits include an analysis of current energy bills. Green mortgages, where a mortgage provider tops up the maximum allowed mortgage with a specific fund for thermal retrofit measures, are explored by the US and the UK governments and advocated by the 2013 European Commission's Climate Action report 'Shifting private finance toward climate-friendly investments' [63]. In the UK, for example, Nationwide, which is one of the biggest mortgage providers in the country, has a product that includes a $£ 20,000$ 'energy improvement' top up of the mortgage, with an interest rate $0.5 \%$ lower than the main mortgage interest rate. This makes it a more beneficial arrangement compared to (now defunct) Green Deal funding. A lower default risk is associated with improved home energy ratings (EnergyStar) in the US, and it has been argued that this should be taken into consideration when underwriting home mortgages [65]. A working market for green mortgages will require standardised building energy performance tools, such as the EPCs, and there is a need for quality assurance for certificate accuracy so that it would reflect behavioural effects.

One of the perceived pitfalls of studies of rebound and prebound effects is the difficulty of correctly estimating building's theoretical heating consumption $C$, which is the heating consumption that would be required to provide full thermal comfort throughout the whole building all year round. 
There are two main difficulties with this metric. One is that it excludes behavioural factors. In order to adjust a building's theoretical energy consumption $(C)$ better to reflect the actual consumption, Majcen et al. [36] used multivariate analysis to predict actual consumption, given dwelling characteristics (including the Energy Performance Certificate, EPC), household characteristics and household behaviour. Their results show that combining these variables can lead to more accurate predicted heating consumption on the level of individual dwellings. They note that including the variables of occupant behaviour and comfort perception would improve accuracy of the EPCs, although this would mean a certificate is no longer valid when a building is occupied by a different user.

Further, to produce a figure for calculated consumption $C$, assumptions have to be made about the thermal quality of a dwelling. These are usually based on long-established laboratory test values for the U-values of walls, together with assumptions about the rate of outdoor air incursion. However, due to consistently high prebound effects in older dwellings, doubt has been cast as to whether the established U-values are correct. A review of such studies is offered in Francis et al. [53], who present their own test results from houses in situ. Although there are methodological difficulties in testing $\mathrm{U}$ values of sections of wall that are physically connected to other walls, windows, floors and materials, a consensus may be emerging that established values are higher than the actual reality, i.e. that older houses 'are [thermally] better than their reputation' [21] (and see discussion in $[66,67]$ ).

If such a consensus is reached and all buildings' U-values are re-scaled by a consistent factor, this will not affect the values of rebound effects. This is because the proportionate change in energy efficiency (and its differential form $\partial \varepsilon / \varepsilon$ in the rebound effect definition) will not be altered by a proportionately consistent change across the energy efficiency axis (a formal mathematical proof of this is presented in [13], pp. 134-135). However, in datasets that include a mixture of older dwellings and newer or retrofitted dwellings with modern insulating materials, the rebound effect will be affected because only the energy efficiency figures of the older dwellings are likely to be reestimated. This will have the effect of reducing rebound effects, though only slightly in countries such as the UK, France or Germany, since by far the majority of dwellings in these countries have the kind of walls whose U-values would be re-estimated. If such changes were to become standardised, the magnitude of the prebound effect would change significantly for older dwellings. A lower U-value means lower calculated consumption, so that actual consumption in older dwellings may be closer to theoretical consumption. This would reduce prebound effects for such dwellings, but not change them for energy-efficient dwellings whose $U$-values are not in dispute. Therefore if $U$-values of older dwellings are to be found significantly lower than the figures commonly in use, this will not challenge the qualitative findings of this paper significantly, but could change them quantitatively: the magnitudes of rebound effects and some prebound effects would need to be recalculated.It is interesting that such a large difference is apparent between rebound effects in French houses and German dwellings. There may be a number of reasons for this, but so far no studies appear to have investigated the differences between the two countries in this regard. Possible factors might be differences in construction techniques, heating systems and climatic conditions, as well as different household lifestyles and behavioural responses to implicit energy costs. As discussed at length in [13], there are two ways of looking at this issue with regard to the rebound effect. In a purist econometric approach, rebound effects are defined solely as behavioural responses to implicit changes in the cost of energy services. To calculate rebound effects under such assumptions would require all the different causes of the change in energy consumption to be disentangled, which, to our knowledge, no research has ever succeeded in doing in relation to thermal retrofits. A second approach is to regard all influences as relevant for rebound effect calculations, as is done in this paper. Questions of specific determinants of energy consumption can be investigated for other research goals, such as policy interventions regarding building substance, heating systems, and user behaviour. 


\section{Conclusions}

This paper explored the conceptual links between prebound and rebound effects and discussed policy implications from quantifying these two behavioural effects.

The study of the mathematical structure of these effects shows that if a prebound effect is high before a retrofit, a high rebound effect after the retrofit is less relevant regarding the total energy savings. A high prebound effect generally indicates that occupants are not getting an adequate level of thermal comfort. A low prebound effect indicates the level of comfort is probably sufficient. A negative prebound effect indicates wastage of energy. Knowing how the prebound effect in a housing stock varies with calculated consumption can help policymakers set sensible minimum thermal standards for retrofits - as illustrated with the German and French datasets.

As a combination of high prebound effect and low income suggests fuel poverty, the prebound effect and household income level can be used as metrics by policy makers to identify which households ('the hidden fuel poor') should be a priority in thermal retrofit policy.

The empirical examples in Section 3 demonstrate the types of cases for which rebound effects are typically investigated: large datasets of heating energy consumption figures and individual retrofit case studies. The main usefulness of the rebound effect in respect of space heating consumption is in attempting to predict what magnitude of actual energy savings are likely in housing stocks, for given magnitudes of average energy efficiency increases, where the total energy consumption of the housing stock is known. However, large rebound effects in specific cases do not necessarily mean heavy energy consumption, either on an absolute or proportionate scale, as demonstrated by the Cambridge case study. This is because the rebound is a ratio between two proportions rather than an absolute value.

A further point concerns the rationale for the concept of the rebound effect. The notion of the rebound effect was developed in the 1980s to provide a way of quantifying the extent to which energy efficiency increases were leading to energy consumption reductions. The fact that it was formulated as an elasticity may be largely because economists were prominent in the initial work on the issue. However, the most basic thing about the rebound effect is not its formulation as an elasticity, but the question of how to produce meaningful information about the behavioural effects, on energy consumption, of energy efficiency increases. Introducing the prebound effect into the discussion gives supplementary information, which can give a fuller picture of how energy consumption levels in this sector are affected by energy efficiency increases.

Further research is needed to understand motivations and practices in households that have high prebound effects.

Aknowledgement: The authors wish to thank Benoit Allibe, Marie-Helen Laurent and Jean-Narie Cayla of Électricité de France, for making data on French houses available for use in this paper, and also three anonymous reviewers, for helpful comments on an earlier draft of the paper.

\section{References}

[1] Kontonasiu E, Atanasiu B, Mariottini F (2015) Tackling fuel poverty with building renovation. ECEEE Summer Study Proceedings 1281-1292.

[2] EED (2012) Directive 2012/27/EU of the European Parliament and of the Council, of 25 October 2012. http://eur-lex.europa.eu/legal-content/EN/TXT/?uri=CELEX:32012L0027

[3] Atanasiu B, Kontonasiou, E, Mariottini F (2014) Alleviating fuel poverty in the EU, investing in home renovation, a sustainable and inclusive solution, Buildings Performance Institute Europe (BPIE), Brussels. 
[4] Sunikka-Blank M, Galvin R (2012) Introducing the prebound effect: the gap between performance and actual energy consumption. Building Research and Information 40(3), 260-273.

[5] Khazzoom, J. Daniel, 1980. Economic implications of mandated efficiency in standards or household appliances. Energy Journal 1 (4), 21- 40.

[6] Khazzoom, J. Daniel, 1987. Energy saving resulting from the adoption of more efficient appliances. Energy Journal 8, 85- 89.

[7] Jevons, William Stanley, 1865/1965. The Coal Question: An Inquiry Concerning the Progress of the Nation, and the Probable Exhaustion of Our Coal-mines, 3rd edition 1905. Augustus M. Kelley, New York.

[8] Saunders H (1992) The Khazzoom Brookes postulate and neoclassical growth. The Energy Journal 13(4): 131.

[9] Barry L, Hirst E (1983) Evaluating utility residential energy conservation programmes: an overview of an EPRI workshop. Energy Policy 18: 77-81.

[10] Berkout, Peter H.G., Muskens, Jos. C., Velthuijsen, Jan W., 2000. Defining the rebound effect. Energy Policy 28 (6/7), 425-432.

[11] Sorrell S, Dimitropoulos J (2008) The rebound effect: Microeconomic definitions, limitations and extensions. Ecological Economics 65: $636-649$.

[12] Galvin R (2014a) Making the 'rebound effect' more useful for performance evaluation of thermal retrofits of existing homes: Defining the 'energy savings deficit' and the 'energy performance gap'. Energy and Buildings, 69: 515-524.

[13] Galvin R (2015b) The Rebound Effect in Home Heating: A guide for practitioners and policymakers. London: Building Research and Information/Earthscan.

[14] Galvin R (2015c) The ICT/electronics question: Structural change and the rebound effect. Ecoligical Economics 120:23-31.

[15] Sorrell S (2007) The rebound effect: an assessment of the evidence for economy-wide energy saving from improved energy efficiency, UKERC, London.

[16] Hermelink AH, de Jager D (2015) Evaluating our Future, The crucial role of discount rates in European Commission energy system modelling, Stockholm: eceee/Ecofys.

[16] Saunders H (2013) Historical evidence for energy efficiency rebound in 30 US sectors and a toolkit for rebound analysts. Technological Forecasting and Social Change 80: 1317-1330.

[17] Galvin R (2014c) Estimating broad-brush rebound effects for household energy consumption in the EU 28 countries and Norway: some policy implications of Odyssee data. Energy Policy 73: 323332.

[18] Cellura M, Guarino F, Longo S, Mistretta M, Orioli A (2013) The role of the building sector for reducing energy consumption and greenhouse gases: An Italian case study. Renewable Energy 60: 586-597.

[19] Maxwell D, McAndrew L, Mudgal S, Cachia F, Muehmel K, Neubauer A, Troltzsch, J (2011) Addressing the rebound effect, final report, European Commission (EC) DG ENV, Brussels.

[20] Ryan L (2011) The impacts of energy efficiency policy - co-benefots and rebound effects, Presentation to CA ESD Core theme 2, 25-26 September 2011, International Energy Agency (IEA), Paris.

[21] Walberg, D., Holz, A., Gniechwitz, T. and Schulze, T. (2011) Wohnungsbau in Deutschland 2011 Modernisierung oder Bestandsersatz: Studie zum Zustand und der Zukunftsfähigkeit des deutschen 'Kleinen Wohnungsbaus'. Arbeitsgemeinschaft fu $r$ zeitgemäßes Bauen, eV, Kiel. 
[22] Schröder F, Altendorf L, Greller M, Boegelein T (2011) Universelle Energiekennzahlen für Deutschland: Teil 4: Spezifischer Heizenergieverbrauch kleiner Wohnhäuser und Verbrauchshochrechnung für den Gesamtwohnungsbestand. Bauphysik, 33(4): 243-253.

[23] Cayla J-M, Allibe B, Laurent M-H (2010) From practices to behaviors: estimating the impact of household behavior on space heating energy consumption, in Proceedings of the ACEEE Summer Study on Energy Efficiency in Buildings, Pacific Grove, CA, US, 15-20 August 2010.

[24] Tighelaar C, Menkveld M (2011) Obligations in the existing housing stock: who pays the bill?, in Proceedings of the ECEEE 2011Summer StudyonEnergyEfficiencyFirst:TheFoundation of a LowCarbon Society, pp. 353-363.

[25] Hens H, Parijs W, Deurinck M (2010) Energy consumption for heating and rebound effects. Energy and Buildings, 42: 105-110.

[26] Kelly, S. (2011) Do Homes that are More Energy Efficient Consume Less Energy?: A Structural Equation Model for England's Residential Sector. EPRG Working Paper No. 1117, Cambridge Working Paper in Economics 1139, University of Cambridge, Cambridge.

[27] Booth A, Choudhary R (2013) Decision making under uncertainty in the retrofit analysis of the UK housing stock: Implications for the Green Deal. Energy and Buildings 64: 292-308.

[28] Motuziene V, Vilutiene T (2013) Modelling the Effect of the Domestic Occupancy Profiles on Predicted Energy Demand of the Energy Efficient House. Procedia Engineering 57: 798 - 807.

[29] Nagy Z, Rossi D, Hersberger C, Domingo Irigoyen S, Miller C, Schlueter A (2014) Balancing envelope and heating system parameters for zero emissions retrofit using building sensor data. Applied Energy, 131: 56-66

[30] Gram-Hanssen K (2014) Retrofitting owner-occupied housing: remember the people. Building Research and Information, 42: 393-397.

[31] Janda K (2014) Building communities and social potential: Between and beyond organizations and individuals in commercial properties. Energy Policy67: 48-55Jevons, William Stanley, 1865/1965. The Coal Question: An Inquiry Concerning the Progress of the Nation, and the Probable Exhaustion of Our Coal-mines, 3rd edition 1905. Augustus M. Kelley, New York.

[32] Tweed C (2013) Socio-technical issues in dwelling retrofit. Building Research and Information, 41: 551-562.

[33] Kanatschnig D, Lacher E (2012) Linking Low Carbon Technologies with Low Carbon Society. Energie 2050: Anforderungen an die Technologiepolitik zur Eindämmung des Rebound-Effektes. Vienna: Bundesministeriums für Verkehr, Innovation und Technologie.

[34] Wade J, Eyre N (2015) The evidence for real energy savings from energy efficiency programmes in the household sector: A report by the UKERC Technology \& Policy Assessment Function. London: UK Energy Research Centre.

[35] IWU (2014) Teilenergiekennwerte von Nichtwohngebäuden (TEK): Querschnittsanalyse der Ergebnisse der Feldphase. Darmstadt: Institut Wohnen und Umwelt.

[36] Majcen D, Itard L, Visscher H (2015) Statistical model of the heating prediction gap in Dutch dwellings: Relative importance of building, household and behavioural characteristics, Energy and Buildings, 105, 43-59.

[37] ARG (Arbeitsgemeindschaft für Zeitgemäßes Bauen e.V. (2013) Steigerung der Energieeffizienz im Gebäudebereich - Potenziale integrierter Quartiersansätze. Kiel: ARG. Available at http://www.deutscherverband.org/cms/fileadmin/medias/kalender/Energieeffizienz_im_Wohnquartier/Leipzig/03_Walber g.pdf accessed 19 August, 2014. 
[38] GBV (Österreichischer Verband Gemeinnütziger Bauvereinigungen) (2013) Energieeffizienz und Wirtschaftlichkeit: Investitions- und Nutzungskosten in Wohngebäuden gemeinnütziger Bauvereinigungen unter besonderer Berücksichtigung energetischer Aspekte. Vienna: GBV. Available at http://www.gbv.at/Document/View/4376 accessed 22 August, 2014.

[39] Gärtner E (2012) Energiewende: Billiges Styropor kann teuer kommen: Wärmedämmung nützt nur der Lobby (und dem Staat). Eigentümlich Frie, 21 December, 2012. Available at http://efmagazin.de/2012/12/21/3924-energiewende-billiges-styropor-kann-teuer-kommen accessed 19 August 2014.

[40] VDGN (Verband Deutscher Grundstücksnutzer) (2013) Sonnenenergie nutzen und Dämmung weglassen? Eine Replik auf das Interview mit dem Architekten Konrad Fischer. VDGN-Journal 4:2013. Available at http://www.vdgn.de/vdgn-journal/2013/vdgn-journal-4-2013/beitrag/xxxxxxxx-3/ accessed 19 August, 2014.

[41] Hanf S (2013) Dämmwahn oder Klimarettung? Vom Sinn und Unsinn der energetischen Sanierung. ZDF Television documentary (screened August 2013). Retrieved August 28, 2013, from http://www.zdf.de/ZDFzoom/D\%C3\%A4mmwahn-oder-Klimarettung-29132014.html

[42] Galvin R (2013) Impediments to energy-efficient ventilation of German dwellings: A case study in Aachen. Energy and Buildings 56: 32-40.

[43] Galvin R (2014d) Are passive houses economically viable? A reality-based, subjectivistapproach to cost-benefit analyses. Energy and Buildings 80: 149-157.

[44] Galvin R (2014e) Why German homeowners are reluctant to retrofit. Building Research and Information 42(4): 398-408.

[45] Galvin R (2015a) 'Constant' rebound effects in domestic heating: Developing a cross-sectional method. Ecological Economics 110: 28-35.

[46] Galvin R (2015d) Integrating the rebound effect: accurate predictors for upgrading domestic heating. Building Research and Information 43(6) 710-722.

[47] Galvin R, Sunikka-Blank M, (2013) A critical appraisal of Germany's thermal retrofit policy, London: Springer.

[48] Rosenow M, Galvin R (2013) Evaluating the evaluations: Evidence from energy efficiency programmes in Germany and the UK. Energy and Buildings 62: 450-458.

[49] Biswanger M (2001) Technological progress and sustainable development: what about the rebound effect? Ecological Economics 36(1): 119-132.

[50] Boardman B (2010) Fixing fuel poverty: challenges and solutions. London: Earthscan.

[51] Herring H, Roy R (2007) Technological innovation, energy efficient design and the rebound effect. Technovation 27(4): 194-203.

[52] Ürge-Vorsatz D, Herrero T (2012) Building synergies between climate change mitigation and energy poverty alleviation. Energy Policy 49: 83-90.

[53] Francis G, Smith A, Biddulph P, Hamilton I, Lowe R, AMavrogianni A, Oikonomou E, Raslan R, Stamp S, Stone A, Summerfield A, Veitch D, Gori V, Oreszczyn T (2015) Solid-wall U-values: heat flux measurements compared with standard assumptions, Building Research \& Information 43(2):, 238252, DOI: $10.1080 / 09613218.2014 .967977$.

[54] Galvin R (2014b) Integrating the rebound effect: accurate predictors for upgrading domestic heating. Building Research and Information (in press):

http://dx.doi.org/10.1080/09613218.2014.988439

[55] Boardman B (2012) Fuel poverty synthesis: Lessons learnt, actions needed. Energy Policy 49: 143-148. 
[56] Deutsche Energie-Agentur (2012) Der dena-Gebäudereport 2012: Statistiken und Analysen zur Energieeffizienz im Gebäudebestand. Berlin: Deutsche Energie-Agentur. Report available online at: http://www.dena.de/publikationen/gebaeude/report-der-dena-gebaeudereport-2012.html Accessed 30 December, 2014.

[57] Milne G, Boardman B (2000) Making cold homes warmer: the effect of energy efficiency improvements in low-income homes. Energy Policy 28: 411-424.

[58] Humphreys M, Hancock M (2007) Do people like to feel 'neutral'? Exploring the variation of the desired thermal sensation on the ASHRAE scale. Energy and Buildings 39: 867-874.

[59] Chappells H, Shove E (2005) Debating the future of comfort: environmental sustainability, energy consumption and the indoor environment, Building Research \& Information, 33:1, 32-40, DOI: $10.1080 / 0961321042000322762$.

[60] Fabbri K (2015) Building and fuel poverty, an index to measure fuel poverty: An Italian case study, Energy, 89: 244-258.

[61] Boardman B (2014) Tackling fuel poverty through a community approach, Proceedings of the BEHAVE conference, 3-4 September, Oxford.

[62] Gillich A, Sunikka-Blank M, Ford A (2015) Marketing, outreach, and workforce engagement for thermal retrofit programs - comparing the US BBNP and the UK Green Deal, Building Research and Information (submitted, under review).

[63] European Commission (2013) Shifting private finance toward climate-friendly investments. CLIMA.A.2/ETU/2013/0035. Directorate-General for Climate Action, European Commission. Available at

http://www.managenergy.net/lib/documents/1364/original_Shifting_private_finance_towards_clim ate_friendly_investments_-_report.pdf Accessed 18 November, 2015.

[64] Ofgem (Office of Gas and Electricity Markets, UK) (2011) Typical domestic energy consumption figures: Factsheet 96 . Available at https://www.ofgem.gov.uk/ofgem.../domesticenergy-consump-fig-fs.pdf Accessed 15 June, 2015.

[65] Sahadi B, Stellberg S, Tian C (2013) Home Energy Efficiency and Mortgage Risks. Washington: Institute for Market Transformation.

[66] Hong S, Oreszczyn T, Ridley I (2006) The impact of energy efficient refurbishment on the space heating fuel consumption in English dwellings. Energy and Buildings 38: 1171-1181.

[67] Dantsiou D, Sunikka-Blank M (2015) Why does energy use feedback not work in workplaces? Insights from social practice theory, ECEEE 2015 - First Fuel Now, Toulon/Hyeres, 1-6 June 2015. 